\title{
TIBBİ KENEVİR VE SAĞLIK: FARMAKOLOJİK BİR DERLEME
}

\author{
MEDICAL CANNABIS AND HEALTH: A PHARMACOLOGICAL REVIEW
}

\author{
Özge BALPINAR * ㅁ, Selim AYTAÇ
}

Ondokuz Mayıs Üniversitesi, Kenevir Araştırmaları Enstitüsü, 55270, Samsun, Türkiye

$\ddot{\mathbf{O Z}}$

Amaç: Kenevir antik çağlardan bugüne dek tedavi amaçlı kullanılmakta olan bir bitkidir. Her ne kadar kullanımı içerdiği psikoaktif bileşenler dolayısıyla sınırlandırılmış olsa da, kenevirin tıbbi yönüne dair araştırmalar literatürde oldukça yoğundur. Cannabis sativa L., içerdiği fitokannabinoidler ile endokannabinoid sistemde gen düzeyinde pek çok değişikliğe sebep olabilmektedir. Endokannabinoid sistemin pek çok patolojik durumda potansiyel bir terapötik hedef olabileceğine dair kanttların derlenmesi hedefiyle bu çalışma ortaya koyulmuştur.

Sonuç ve Tartışma: Endokannabinoid sistem içerisinde yer alan reseptörler, endokannabinoidler veya enzimlerin ekspresyon seviyelerinde meydana gelen değişiklikler, Parkinson, Alzheimer, Huntington gibi hastalıkların patolojileriyle ilişkili olabilmektedir. Aynı zamanda endokannabinoid sistemde meydana gelen değişikliklerin kanser hücrelerinin metastazl, yayllımı, proliferasyonunu etkileyebilmektedir. Buna ek olarak kannabinoidlerin, dolayısıyla kenevirin, nöropatik ă̆rının tedavisinde rol oynadı̆̆ gösterilmiştir. Günümüzde kemoterapiye bağlı bulantı ve kusma tedavisinde kullanılan dronabilon ve nabilon kapsülleri gibi bazı kenevirtemelli tedavi preparatları pek çok ülkede onaylanmış, kullanıma sunulmuştur. 49tetrahidrocannabinol/ cannabidiol oromukozal sprey gibi preparatlar da pek çok bölgede kanser hastalarında analjezik olarak ya da multiple skleroz hastalarının kas spastisitelerinin giderilmesinde kullanımı onaylanan preparatlardandır. Ancak endokannabinoid sistemin terapötik etkinlik üzerindeki önemi dikkate alındığında, daha pek çok tıbbi durum için kenevirin standardize edilmiş preparatlarına ve bu doğrultuda daha fazla araştırmaya ihtiyaç duyulmaktadır.

Anahtar Kelimeler: Kannabinoid, kanser, kenevir, nörodejeneretif hastalıklar.

\section{ABSTRACT}

Objective: Cannabis sativa L. is a plant that has been used for therapeutic purposes since ancient times. However, its use has been limited due to its content. Cannabis causes many changes at the gene level in the endocannabinoid system with the phytocannabinoids it contains. The aim of this study was to provide evidence that the endocannabinoid system could be a potential therapeutic target in many pathological conditions.

\footnotetext{
Sorumlu Yazar / Corresponding Author: Özge Balpinar

e-posta / e-mail: ozge.balpinar@omu.edu.tr, Tel. / Phone: 03623121919/6464
} 
Result and Discussion: The change in the expression levels of receptors, endocannabinoids or enzymes in the endocannabinoid system may be associated with the pathologies of diseases such as Parkinson, Alzheimer, and Huntington. Besides, changes in the endocannabinoid system can affect the migration, proliferation of cancer cells. Also, cannabinoids, have been shown to play a role in the treatment of neuropathic pain. Today, some cannabis-based treatment preparations such as dronabilon and nabilon capsules used in the treatment of chemotherapy-induced nausea and vomiting have been approved and available in many countries. Preparations such as 49 tetrahydrocannabinol/cannabidiol oromucosal spray are also among the preparations approved for use as analgesic in cancer patients or for the relief of muscle spasticity in multiple sclerosis patients. However, standardized preparations of cannabis and further research are needed for many other medical conditions.

Keywords: Cancer, cannabinoid, cannabis, neurodegenerative diseases

\section{GíRIŞ}

Kenevir (Cannabis sativa L.), 104'ü tanımlanmış kannabinoid olmak üzere 500'den fazla bileşik içeren psikoaktif etkilere sahip bir bitkidir. Kannabinoid bileşiklerinin ismi de kenevirin latince isminden köken almaktaktadır. Bu bitki psikoaktif etkileri sebebiyle çok eski zamanlardan bu yana tıbbi amaçlarla kullanılmaktadır $[1,2]$.

Geleneksel Çin tıbbında astım, sıtma ve gut hastalığı tedavisi için kullanılan kenevirin, Hindistan'da migren, konvülsiyonlar ve nevralji için kullanıldığı belirlenmiştir [3, 4]. Ondokuzuncu yüzyılda Avrupa ve Amerika'da kenevirin etanolden elde edilmiş ekstraktlarının oldukça popüler bir konuma eriştiği bilinmektedir. Bu ekstraktlar hayatı tehdit eden yenidoğanlarda konvülsiyonlar, tetanos, kolera ve kuduz gibi hastalıkların tedavilerinde kullanılmıştır. Ancak yirminci yüzyılın ilk yarısından itibaren kenevirin bu şekilde terapötik kullanımları, belirli bir standartta kenevir preparatlarının hazırlanamaması sebebiyle ortadan kaybolmuştur [5].

Kanada, Amerika Birleşik Devletleri ve İngiltere'deki eczanelerin raflarında yıllarca yer almakta olan kenevir, psikoaktif etkileri sebebiyle eleştirilere maruz kalmış, suç sayılmış ve 1970'li yıllarda yasadışı bir uyuşturucu olarak listelenmiştir. Bunun sebebi içeriğinde yer alan tetrahidrokannabinol gibi bazı fitokannabinoidlerin psikoaktif niteliklerinin suistimal edilmesi, kötüye kullanılması, bağımlılığa yol açabiliyor olmasıdır. 2014 yılında tarım yasasının yürürlüğe girmesiyle birlikte "endüstriyel kenevir" tanımı yapılmış, bu doğrultuda en fazla $\% \quad 0,3$ oranında tetrahidrokannabinol içeriğine sahip kenevir bitkilerinin araştırma amaçlı yetiştirilmesine izin verilmiştir. Ancak son 15-20 yıl içerisinde çeşitli rahatsızlıklar ve hastalıklar için kenevirin terapötik etkileri değerlendirilmek istenmiş, bu süreç de esrar içeriği ile kendisinden söz ettiren kenevirin pek çok yerde suç olmaktan çıkarılması, yasal bir forma eriştirilmesi ve bitkiye yönelik ilginin artırılması ile sonuçlanmıştır [6].

\section{Kenevir Bitkisinin Botanik Özellikleri}

Kenevir, botanik tanımlaması Cannabis sativa L. olan, ülkemizde bölgeden bölgeye değişen kendir, çetene, kınnap, kendirik tanımlamalarına sahip bitkidir [7]. Urticales takımının Cannabinaceae 
familyası içerisinde Cannabis cinsi kapsamında yer almaktadır. Dioik bir bitki olan kenevirde, erkek ve dişi çiçekler aynı zamanda çiçek açmamaktadır. Tarımı yapılan kenevir bitkisinin kromozom sayısı $2 n=20$ olarak belirlenmiştir [8].

Kazık köklü, dik gövdeli bir bitki olan kenevirin yüksekliği 1-6 m arasında değişiklik göstermektedir. Karş11ıklı veya alternan olarak dallanan bitkinin kökleri 30-60 cm derinliğe ulaşırken, gevşek topraklarda bu ölçüm 2.5 metreye kadar çıkabilmektedir [9]. Tohumları 3-6 mm uzunluk, 2-4 mm genişliğe sahiptir. Türden türe değişmekle birlikte tohum renkleri genellikle gri, siyah, yeşilli koyu tonlardadır, tohum kabuğu incedir [10].

Kenevir içeriğinde kannabinoidlere ek olarak, 20'den fazla flavonoid tanımlanmıştır. Bitki içeriğinde yer alan flavonoidlerin anti-enflamatuvar, anti-alerjik ve sitoprotektif etkilere sahip olduğu belirlenmiştir. Flavonoidlere ek olarak kenevirde yer alan bir diğer fitokimyasal grubu da terpenlerdir. Terpenler kenevirin karakteristik kokusunun kaynağı olarak bilinmektedir. Hem monoterpenler hem de seskuiterpenler kenevirin köklerinde ve üst yapılarında tespit edilmiştir [11].

\section{Kannabinoidler ve Endokannabinoid Sistem}

Kenevir içeriğindeki en güçlü ve ana bileşen olarak bilinen madde $\Delta 9$-tetrahidrokanabinoldür (THC). Cannabis sativa L. içerisinde THC'ye ek olarak $\Delta 8$-tetrahidrokanabinol ( $\Delta 8$-THC), kannabinol $(\mathrm{CBN})$ gibi fitokannabinoidler de bulunmaktadır. Bu maddelerin kenevir içeriğinde THC'ye kıyasla daha düşük oranda bulunduğu ve endokannabinoid sistem reseptörlerine daha düşük afinite ile bağlandıkları bilinmektedir [12,13]. Bunlara ek olarak son dönem bilimsel çalışmalarda sıkça görülen, popüler bir fitokannabinoid olmasıyla pek çok Cannabis preparatında da yer alarak adından sıkça söz ettiren bir diğer kannabinoid kannabidioldür (CBD). Kannabidiol THC'nin \%10'u kadar aktivite sergiler ve psikoaktif bir bileşen değildir [8]. Ayrıca CBD, anksiyolitik ve antipsikotik özellikler sergilemektedir $[14,15]$. CBD'nin THC etkisi ile ortaya çıan psikotropik özellikleri hafifletebilme potansiyeline sahip olduğu bilinmektedir [16].

1990’lı yıllarda, yukarıda sözü edilen bileşiklerle ilişkili spesifik reseptörlerin varlığ tespit edilmiştir. Böylece kannabinoidlerin membran reseptörleri aracılı̆̆ 1 ile etkilerini ortaya koydukları belirlenmiştir. Reseptörlerin keşfedilmesi, reseptörlerin aktifleşmesini sağlayan endojen nitelikli kannabinoidlerin yani endokannabinod ligandların araştırılmasına öncülük etmiştir. Bugün kannabinoid terimi ile hem bitkisel kaynaklı fitokannabinoidler hem endokannabinodiler hem de her iki grubun sentetik analogları ifade etmektedir. Bugüne kadar CB1 ve CB2 olmak üzere iki adet kannabinoid reseptörü üzerinde yoğunlaşılmıştır [17,18]. CB1 reseptörünün büyük çoğunlukla merkezi sinir sisteminde (MSS) yer aldığı, buna ek olarak periferik sinir hücrelerinin terminallerinde de bulunduğu belirlenmiştir. CB1 nöronal olmayan dokularda da yayılıma sahiptir; rahim, prostat, testis, mide, vasküler endotelyal sistem ve iskelet sistemi gibi dokularda da CB1 reseptörünün yaygın bir biçimde dağılım sergilediği görülmektedir. CB2 reseptörü ise CB1'e kıyasla daha sınırlı bir dağ1lıma sahiptir. 
CB2 reseptörleri temel olarak immün sistemde yer almakta, hem immün sistemle ilişkili dokularda hem de immün sisteme ait hücrelerde bulunmaktadır $[19,20]$. Ancak CB2 reseptörleri inflamasyon gibi bazı durumlar ortaya çıktığında MSS'de yer alan glial hücrelerde de görülmektedir [21,22].

Kannabinodilerin tamamı etkilerini yalnızca $\mathrm{CB} 1$ ve $\mathrm{CB} 2$ reseptörleri üzerinden sergilememektedir. $\mathrm{Bu}$ süreçte hem endokannabinoidler hem de bitkisel kaynaklı kannabinoidlerin tamamı GPR55 ve GPR19 gibi G-protein kenetli reseptörler üzerinden etkilerini gösterebildiği gibi, TARPA1, TRPV1 ve TRPV2 gibi katyon kanalları üzerinden de etkilerini sergileyebilmektedir. GPR55 reseptörünün $\mathrm{CB} 1$ ve $\mathrm{CB} 2$ reseptörleri gibi endokannabinoid sistemin bir parçası olduğu düşünülmektedir [23].

Endokannabinoid sistem içerisinde, kannabinoid reseptörleri, endokannabinoidler ile bu maddelerin biyosentezi ve yıkımlarından sorumlu enzimler yer almaktadır. Endokannabinoid sistem, son döneme ait pek çok çalışmada patolojik durumların muhtemel bir terapötik hedefi olarak değerlendirilmiştir. $\mathrm{Bu}$ sistemin enerji dengesinin sağlanması, iştah uyarımı, kan basıncı, analjezi, bulantı ve kusmanın kontrol altına alınması, hafıza, öğrenme, bağışıklık sisteminin tepkilerinin düzenlenmesi gibi pek çok fizyolojik süreçte katılım gösterdiği bilinmektedir [24-27].

Bunlara ek olarak endokannabinoid sistemin bazı patolojik durumlarda koruyucu rol üstlendiği de bilinmektedir. endokannabinoid maddelerin seviyelerinde meydana gelen değişiklikler Parkinson, Huntington ya da multiple skleroz (MS) gibi nörolojik hastalıklara sebep olduğu gibi iştahsızlık veya irritabl bağırsak sendromu gibi durumlara da sebep olabilmektedir. Endokannabinoid sistem içerisindeki değişiklikler kontrolsüz proliferasyon, migrasyon ile karakterize kanser hastalıklarıyla da ilişkilendirilmektedir [28-32].

\section{Kenevir ve Nörolojik Hastalıklar}

\section{Multiple Skleroz (MS)}

Multiple skleroz hastalarında MS hastalığg ile birlikte endokannabinoid sistem içerisinde bazı sistem üyelerinin ekspresyon seviyelerinde değişimler olduğu tespit edilmiştir. Ölüm sonrası MS donörlerinin beyin dokularında CB1 ve CB2 reseptör ekspresyonlarında artış gözlendiği kaydedilmiştir [33]. Farklı alt tiplerde MS hastalığına sahip hastalardan alınan plazma örneklerinde, tüm numunelerde birkaç endokannabinoid seviyesinde artış olduğu kaydedilmiştir. Yalnızca ilerleyici MS (Primer progresif MS) hastalarında $\mathrm{CB} 1$ ve $\mathrm{CB} 2$ reseptörlerine ait ekspresyon seviyelerinde artış tespit edilmiştir. İkincil MS hastalarında ise endokannabinoidlerin bir kısmının yıkımından sorumlu bir enzimin ekspresyon seviyesinin azaldığı görülmüş, buna bağlı olarak bu hastaların plazmalarında ilgili endokannabinoid seviyesinin arttı̆̆ı belirlenmiştir [34].

Kenevirin ve kannabinoidlerin MS hastalığındaki etkisini ve önemini belirlemek, hastalığın tedavisinde, semptomların kontrol altına alınmasındaki yerini ortaya koyabilmek adına çeşitli klinik çalışmalar gerçekleştirilmiştir. 2,5 ve $5 \mathrm{mg}$ dozlarında oral yolla kullanılan Cannabis sativa L. 
ekstraktları ile $\Delta$ 9-THC'nin MS hastalığında ortaya çıkan kas spastisitesini iyileştirmede yetersiz kaldığı tespit edilmiştir [35]. Bu konuda gözle görülür bir iyileşme kaydedebilmek adına 7,5 mg dozunda $\Delta 9$ THC kullanımının gerekli olduğu belirlenmiştir [36].

Kenevir ekstraktının tedavide kullanıldığı MS hastalarında kas sertliğinde plasebo grubuna kıyasla iki kata yakın bir gelişim görüldüğü kaydedilmiştir [37]. Kas spastisitesinde test edilen THC/CBD oromukozal sprey olan SativexTM'in kenevir ekstraktları veya THC'nin oral uygulamalarına kıyasla etki seviyesinin daha düşük olduğu belirlenmiştir [38, 39].

Multiple Skleroz ile ilişkili kaslarda ortaya çıkan sertlik, spastisite gibi semptomlarda kontrol gruplarına kıyasla kannabinoid ile tedavi gören hastalarda göreceli bir iyileşmenin olduğu kaydedilmiştir. Yapılan çalışmalardaki sonuç farklılıkları, çalışmaların tasarımlarının, kullanılan tedavi dozlarının farklılığı ile ilişkili olduğu düşünülmektedir. Bunlara ek olarak çalışmalarda MS tedavisi için kannabinoid kullanan hastalarda baş dönmesi, uyku hali, baş ağrısı, ağız kuruluğu gibi advers etkilerin ortaya çıktığı görülmüştür [40].

\section{Epilepsi}

Epilepside ortaya çıkan eksitotoksisite (glutamatın sinaptik aralıkta anormal ve aşırı artışı) durumuyla ilişkili olarak endokannabinoid sistemin bir role sahip olup olmadığ 1 araştırmalara konu olmuştur. Bu amaçla gerçekleştirilen bir çalışmada fare modellerinde CB1 reseptörlerinin kainik asit kaynaklı eksitotoksisiteye karşı korumada rol sahibi olduğunu ifade etmiştir. Bu doğrultuda CB1 reseptörüne ait geni ihtiva etmeyen farelerin, CB1 reseptörüne sahip farelere kıyasla çok daha şiddetli nöbetler geçirdiği kaydedilmiştir. Buna ek olarak CB1 reseptörüne sahip farelerde endokannabinoid olan araşidonil etanolamin (Anandamid; AEA) seviyelerinin hipokampus bölgesinde arttığı gözlenmiş, bu durumun da endokannabinoid sistemin eksitotoksisiteye karşı koruyuculuğu ile ilişkili olduğu düşünülmüştür [41].

Preklinik çalışmalarda endokannabinoid sistemin epileptik nöbetlerle, eksitotoksisiteye karşı koruma sağlamasıyla ilişkili olarak elde edilen verilerin akabinde epilepsi hastalarıyla da bazı klinik çalışmalar gerçekleştirilmiştir. Girişimsel olmayan birkaç çalı̧̧mada antiepileptik ilaçlarla birlikte kenevirin hava yolu ile tüketiminin nöbetlerin kontrolünde etkili bir yaklaşım olabileceği bildirilmiştir [42-44]. Buna benzer başka bir çalışmada ise kenevirin benzer kullanımının epilepsi hastalarının nöbetlerini etkilemediği ifade edilmiştir [45].

Kenevir ekstraktlarıyla yapılan bir çalışmada çocuk epilepsi hastaları üzerinde CBD ile zenginleştirilmiş kenevir ekstraktları test edilmiştir. Elde edilen verilere göre gerçekleştirilen tedavi ile hastaların \%84'ünde nöbet sıklığının azaldığı kaydedilmiştir. Buna ek olarak uygulanan tedavinin davranış, uyku ve uyanıklıkla ilgili de iyileşme sağladığı belirlenmiştir [46, 47].

EpidiolexTM CBD oral solüsyonunu kullanan febril nöbetli epilepsi hastası 7 kişiden 6'sında nöbet sıklığının ve süresinin iyileştiği bildirilmiştir [48]. Yüksek THC, düşük CBD içeriğine sahip 
keneviri kullanan epilepsi hastası çocuklarda, kullanmayanlara kıyasla daha şiddetli nöbetlerin gerçekleştiği belirlenmiştir. Çalışmalardaki farklı sonuçların, kullanılan kenevir ekstraktların içeriğindeki etken maddelerin oranlarının değişikliğiyle ilişkili olduğu ifade edilmektedir. Bu durumda nöbetlerin tedavisinde CBD en umut verici kannabinoid olarak görülmektedir [49].

\section{Parkinson}

Endokannabinoid sistemin özellikle bazal ganglionlarda yüksek ekspresyon seviyesine sahip olduğu görülmüştür. $\mathrm{Bu}$ durumun hareket kontrolü ile ilişkisinin incelenmesi neticesinde, endokannabinoid sistem aktivasyonunun motor inhibisyonla ilişkili olduğu belirlenmiştir [50, 51]. Parkinson hastası bireylerden ölüm sonrası alınan beyin örneklerinde bazal ganglianın bazı bölümlerinde CB1 reseptörlerinin ekspresyonlarında azalma gözlendiği ifade edilmiştir. Nükleus akümbens, ön ile arka ventral putamen ve substantia nigra bölümlerinde ise CB1 reseptörü ekspresyon seviyesi değişiklik arz etmemiştir [52].

Parkinson hastalığının farklı aşamalarında olan hastalardan alınan beyin omurilik sıvısı örnekleri incelendiğinde, AEA endokannabinoidinin seviyesinin hastalık evresinden bağımsız bir biçimde normale kıyasla iki kat artış gösterdiği kaydedilmiştir [53].

Parkinson modeli oluşurulmuş sıçanlarda yapılan bir çalışmada CB1 reseptörünün bloke edilmesi antiparkinson etki meydana getirmiştir. Rimonabant olarak bilinen (SR141716A) CB1 reseptör antagonistinin striatum, globus pallidus ve subtalamik çekirdeğe uygulanmasıyla parkinsonlu farelerde motor asimetrinin azaldığı ortaya koyulmuştur [54]. Bir başka çalışmada rimonabantın orta düzey LDOPA tedavisinin etkisini artırdığı ortaya konulmuş, tedaviye eklenmesi gerektiği öne sürülmüsstür [55]. Ancak ayn ilacın kemirgenlerdeki etkisinin aksine, primatlarda antiparkinson aktivite sergilemediği görülmüştür [56]. Konu ile ilişkin vaka raporlarına rastlamak mümkün olsa da, Parkinson hastalığı ile ilişkili olarak kontrollü bir klinik çalışmanın eksikliği literatürde göze çarpmaktadır.

\section{Alzheimer}

Alzheimer hastalarından elde edilen beyin dokusu örneklerinde endokannabinoid sistem üyelerinin ekspresyonları incelenmiştir. Amiloid beta lpakları bakımından zengin olan beyin bölgelerinde AEA endokannabinodinin yıkımından sorumlu olan yăg asidi amid hidrolaz (FAAH) enzimi ile CB2 reseptörünün genlerinin ekspresyonlarında artış kaydedilmiştir. FAAH enzim aktivitesinin de arttığ , ancak CB1 seviyesinin değişmediği belirlenmiştir [57]. Buna ek olarak başka bir çalışmada CB1 reseptör ekspresyonunun azaldığı da ifade edilmiştir [58].

Alzheimer hastalığı ile artan CB2 reseptör ekspresyonu seviyesini ilişkilendiren çalışmaların ardından [59, 60]; yeni terapötik yaklaşımlar için CB2 agonistlerinin kullanımı spesifik olarak hedeflenmiştir. Seçici bir CB2 agonisti olan JWH-015 in vitro olarak gerçekleştirilen bir çalışmada amiloid beta plaklarının insan dokularından uzaklaşmasını sağlamıştır [61]. 
Selektif bir CB2 agonisti olan MDA-7 etken maddesi, 14 gün süreyle alzheimer hastalığına sahip sıçanlara intraperitoneal yolla uygulanmıştır ve bu sürenin sonunda amiloid beta birikiminde azalma ile kognitif bozuklukta iyileşmeler gözlenmiştir [62].

Reseptör agonisti etken maddelerine ek olarak, bu reseptörlere düşük afiniteye sahip CBD de Alzheimer hastalığı için faydalı etkiler ortaya koymuştur. 7 gün süreyle 2,5 veya $10 \mathrm{mg} / \mathrm{kg} / \mathrm{gün}$ dozlarında intraperitoneal yolla CBD alan Alzheimer hastalarda amiloid beta birikimi ile uyarılan nöroinflamasyonun azaldığı kaydedilmiştir [63].

\section{Huntington}

Huntington hastalığı ile ilişkili beyin bölgelerinde endokannabinoid sisteme dair yapıların ekspresyon seviyelerinin değiştiğine dair pek çok çalışma mevcuttur. Bu çalışmalar endokannabinoid sistemin huntington hastalığının patolojisinde rol sahibi olduğunu düşündürmektedir. Huntingtona sahip hastaların beyinlerinin ölüm sonrası incelenmesi ile gerçekleştirilen bir çalışmada bazal ganglia ile özellikle globus pallidusta CB1 reseptörlerinin ekspresyon seviyelerinin \%97,5 kadar azaldığ1 kaydedilmiştir [64, 65]. Kemirgen modellerini içeren huntington çalışmaları da bu sonucu destekler niteliktedir [66-68].

Yapılan bazı klinik çalışmalarda hem oral CBD hem de THC/CBD oromukozal sprey uygulamaları test edilmiştir. Yapılan çalışmalarda huntington hastalarında motor, bilişsel ve fonksiyonel semptomlarda bir iyileşme kaydedilememiştir $[69,70]$. Ancak yapılan bir başka klinik pilot çalışmada nabilonun kognitif sorunların giderilmesinde etki kaydedildiği ifade edilmiştir [71].

\section{Kenevir ve Ağrı}

Ağrının tedavisi için esrar içerikli kenevirin kullanımı 5000 yıl öncesine dayanmaktadır. Ancak kullanımı bu kadar eskiye dayanıyor olmasına rağmen, etki mekanizmaları ile ilişkili olarak yeterli bilgi mevcut değildir. Kannabinoidler ya da kannabinoid içeren farmasötik preparatlar çoğunlukla somatosensör sistemi etkileyen lezyonlar ile hastalıklarla ilişkili olarak ortaya çıkan nöropatik ağrının hafifletilmesi için kullanılmaktadır [72]. Yapılan çalışmalar THC'nin nöropatik ağrıyı hafifletmek üzere etkili bir ajan olduğunu ortaya koymuştur. Ancak elde edilen verilerde THC'nin endişe verici yan etkileri olduğu kaydedilmiştir [73-75].

Kannabinoidlerin analjezik olarak kullanımı, daha çok opioid gibi diğer analjezik ilaçlara alternatif bulma hedefi dolayısıyla ortaya çıkmıştır. Hava yoluyla kenevirin kullanımınının ağrı üzerindeki etkisini araştıran bir çalışmada artan THC oranıla birlikte katılımcıların hissettikleri ağrı derecesinin de azaldığını bildirdiği kaydedilmiştir [76]. Genel olarak kenevirin analjezik etkisinin hafif olduğu, özellikle bu amaçla reçete edilen GABA reseptör agonistleri gabapentin ve pregabalin gibi ilaçlar kadar etkili olmadığı ifade edilmektedir. Bu sebeple kenevirin dolayısıyla kannabinoidlerin tek başlarına kullanımı yerine mevcut analjezik ilaçlarla birlikte kullanımının daha etkili olduğu düşünülmektedir. Mevcut ağrı kesici ilaçlarla birlikte kullanılan SativexTM ticari adıyla bilinen 
Nabiximols (Eşit derecede THC ve CBD içerir.) gibi oromukozal spreylerin ağrı yoğunluğunda önemli ölçüde azalmaya yardımcı olduğu kaydedilmiştir [74, 77, 78].

Tıbbi kenevirin analjezik etkinliği üzerine klinik çalışmaların sistematik olarak sonuçları incelendiğinde, tıbbi kenevirin nöropatik ağrıyı azaltmada akut etkisinin mevcut olduğu ifade edilmiştir. Plasebo ile kıyaslandığında, ağrının giderilmesi noktasında \% 30 kadar bir analjezik etkiden söz etmenin mümkün olduğu bir çalışmada, mevcut ağrı kesici ilaçlarla kıyaslama yapıldığında istatistiksel olarak anlamlı bir farklı1ık gözlenememiştir [79].

Romatizmal ağrıların giderilmesinde kannabinoidlerin etkisi ile ilişkili verilerin yeterli düzeyde olmadığı düşünülmektedir. Fibromiyalji, romatoid artrit, kas/iskelet ağrısı gibi durumlarda kullanılan THC/CBD oromukozal spreylerinin tedavisini araştıran birkaç randomize klinik çalışmada elde edilen veriler, analjezik olarak kullanım amacıyla kannabinoidlerin önerilmesi için yeterli olarak görülmediğini ortaya koymuştur [80, 81].

\section{Kenevir ve Kanser}

Çeşitli kanser türlerinde endokannabinoid sistem üyelerinin ekspresyon seviyelerinde değişiklik olduğu kaydedilmiş ve bu değişikliklerin kanser tedavisi için potansiyel bi gelişmeye zemin hazırlayabileceği ifade edilmiştir [82].

Yapılan çalışmalarda hem glioblastoma kanser türünde hem de pediatrik gliomaların erken evrelerinde CB1 reseptörlerinin aşırı seviyede eksprese edildiği kaydedilmiştir [83, 84]. Glioblastomalarda ve astrositomlarda ise CB2 reseptörlerinin yüksek seviyede eksprese edildiği ve bu ekspresyon seviyelerinin tümörün içerisinde bulunduğu evre ile de ilişkili olduğu belirlenmiştir [84-87]. Beyin kanseri hücre hatları (U87, 251, C6, H4) ile gerçekleştirilen bir in vitro çalışmada anandamidin antiproliferatif etki sergilediği tespit edilmiştir. Buna ek olarak aynı materyalin migrasyon ile yayılımını da engellediği belirlenmiştir [88, 89]. Diğer endokannabinoidlerin test edildiği bir başka çalışmada C6 glioma hücrelerinin çoğalmasının kannabinoid reseptörleri aracılığıyla engellendiği kaydedilmiştir [90, 91].

Gögüs kanseri hücrelerinde CB2 reseptörlerinin aşırı ekspresyonu bildirilmiştir. HER-2 pozitif olan göğüs kanseri dokularının \%90'ından fazlasında CB2 reseptörlerinin aşırı ekspresyonuna rastlanmıştır [92]. In vitro bir çalışmada test edilen endokannabinoidlerin CB1 reseptörlerini kullanarak meme kanseri hücrelerinde antiproliferatif etki sergilediği gösterilmiştir [93, 94]. Benzer şekilde hem baz1 fitokannabinoidlerin (THC ve CBD dahil) hem de sentetik kannabinoidlerin (WIN-55,212-2 ve JWH-133 gibi) kannabinoid reseptörlerini kullarak antiproliferatif etki sergilediği tespit edilmiştir [95, 96].

Prostat kanseri dokusunun, sağlıklı prostat dokusu ile kıyaslandığında hem CB1 hem de CB2 reseptörlerinin artan ekspresyonuna sahip olduğu belirlenmiştir. CB1 reseptörlerinin aşırı eksprese edilmesinin hem metastaz sıklığını hem de Gleason skorunu etkilediği ifade edilmiştir [97-100]. 
Gerçekleştirilen çalışmalar kannabinoidlerin prostat kanseri dokusunda antiproliferatif etki sergilediğini ortaya koymuştur. Primer in vitro kültürü gerçekleştirilen prostat kanseri kültürü ile PC-3, DU145, LNCaP prostat hücre hatlarında anandamidin CB1 reseptörünün aracıllğ sergilediği belirlenmiştir [99, 101, 102].

Hepatokarsinomda endokannabinoid sistem ekspresyon seviyelerinin araştırıldığ çalışmalarda; sağlıklı karaciğer dokusu ile kıyaslandığında hem CB1 hem de CB2 reseptörlerinin sirasıyla 3.07 ve 5.44 kat fazla eksprese edildiği belirlenmiştir. Anadamid ise karaciğer kanser dokusunda endokannabinoid sistem reseptörlerinden bağımsız bir biçimde proliferasyonu engelleyici etki sergilediği kaydedilmiştir $[103,104]$. Buna ek olarak fitokannabinoidler ile sentetik kannabinoidlerin sitotoksik etkilerinin CB2 reseptörleri aracılığıyla gerçekleştiği tespit edilmiştir [105-107].

\section{Kenevir ve Bulantı/Kusma}

Kenevir bulantı kusma tedavisi için ilk defa 1975 'te yapılan bir çalışma ile kemoterapi alan hastalarda test edilmiştir. THC'nin oral formunun antiemetik özelliklerini araştıran çalışmada, ilgili maddenin bulantının tedavisinde etkili bir ajan olduğu tespit edilmiştir [108].

Sivri fare (Cryptotis parva) hayvan modelinde yapılan bir çalışmada CB1 reseptörlerinin antiemetik etkinlikteki rolü tespit edilmeye çalışılmıştır. Bu amaçla CB1 reseptörlerinin spesifik antagonistler kullanılarak antagonize edilmesinin kusmaya sebep olduğu kaydedilmiştir. CB1 reseptörüne spesifik olan seçici agonistlerin ( $\triangle$ 9-THC, CP 55,940 ve WIN 55,212-2 kullanımıyla kusma etkisi geri döndürülebilmiştir [109].

Gerçekleştirilen farklı çalışmalarda da benzer sonuçlar elde edilmiştir. Fare hayvan modelinde sisplatin kaynaklı kusmanın tedavisinde intraperitoneal olarak uygulanan $\Delta 9$-THC'nin, hem farelerde kusmayı hem de kusma sıklığını azalttığı belirlenmiştir. Aynı çalışma sivri fare (Cryptotis parva) hayvan modelinde de benzer sonuçlar ortaya koymuştur [110].

Yapılan bir klinik çalışmada bulantı ve kusmanın kontrolünde Nabilonun (CesametTM) (1 mg) etkisi test edilmiştir. Elde edilen bulgulara göre kemoterapi öncesinde ve kemoterapi esnasında oral olarak kullanılan proklorperazin veya domperidon $(20 \mathrm{mg})$ ilaçlarına kıyasla Nabilonun daha etkili olduğu belirlenmiştir [111]. Kemoterapiye bağlı bulantı ve kusmayı engelleme amacıyla gerçekleştirilen bir klinik çalışmada MarinolTM, SyndrosTM ticari preparatları içerisinde de yer alan Dronabinol etken maddesi test edilmiştir. Oral yoldan kullanılan Dronabinolün $(2,5 \mathrm{mg})$ intravenöz olarak uygulaması gerçekleştirilen ondansetronla $(16 \mathrm{mg})$ kıyaslandığında benzer etki sergilediği görülmüştür. Her iki ilaç da birlikte kullanıldığında elde edilen etkide bir artış gözlenmediği ifade edilmiştir [112].

Lösemi, lenfomalar, beyin karsinomları dahil pek çok kanser türüne sahip 18 yaş altı çocuklarla gerçekleştirilen bir çalışmada, kemoterapi kaynaklı bulantı ve kusmanın tedavisinde nabilonun etkisi incelenmiştir. Tedavide uygulanan antiemetik ajanla kombine olarak kullanılan oral uygulanan Nabilonun antiemetik etkisinin zayıf olduğu tespit edilmiştir. Kannabinoidlerin diğer yaygın etkileri 
(baş dönmesi, öfori, gevşeme vb.) Nabilon alan hastalarda tespit edilmiştir. Elde edilen bu verilerin farklı olmasının uygulanan kemoterapi programlarıyla ilişkili olduğu düşünülmüştür [113].

Ameliyat sonrası bulantı kusma tedavisi için kannabinoidlerin etkisinin incelendiği bir çalışmada, $\Delta 9$-THC'nin intravenöz uygulamalarının hedeflenen antiemetik etkiye ulaşmadığı kaydedilmiştir. $\Delta 9$-THC düşük antiemetik etkinin yanında, hastalarda psikotropik yan etkiler de ortaya çıkarmıştır [114].

\section{Kenevir ve İnflamasyon}

Cannabis sativa L. içeriğinde yer alan kannabinoidler anti-inflamatuar potansiyellerinin belirlenmesi adına araştırmalara konu olmaktadır. Anti-inflamatuar etkinlik olarak kenevir içeriğinde yer alan kannabinoidlerden hem $\triangle 9$-THC'nin hem de CBD gibi psikoaktif olmayan kannabinoidlerin rol üstlendiği belirlenmiştir.

CBD’nin anti-inflamatuar etkisinin kannabinoid reseptörleri, adenozin A2A reseptörleri, TRPV1 reseptörleri, GPR55 reseptörleri CB2/5HT1A heterodimerizasyonu üzerinden etki gösterebileceği düşünülmektedir [115]. Sıçanlarda kimyasal katkı maddesi E-407 (Karragenan) ile indüklenen bir inflamasyon modelinde CBD'nin COX aktivitesini, PGE2, nitrik oksit ve monoaldehit üretimini de azalttığı kaydedilmiştir [116]. Buna ek olarak CBD’nin HaCaT hücreleri kullanılarak oluşturulan in vitro alerjik dermatit modelinde sitokin üretimini önemli ölçüde azalttığı tespit edilmiştir [117].

Bağışıklık sisteminin aktif hücreleri arasında yer alan monositler, makrofajlar, bazofiller, lenfositler, dendritic hücreler gibi hücrelerde endokannabinoid sistem ürünlerine, enzimlerine ve reseptörlerine rastlanmıştır. Kannabinoidlerin bu hücreler üzerindeki rollerinin bağışıklık sistemini otokrin ve parakrin olarak module etmek olduğu bilinmektedir [118].

Sentetik kannabinoid olan JWH-018'in CB2 reseptörleri üzerindeki tam agonist etkisi aracılığıyla immün sistemin düzenlenmesinde hatta immün sistemin baskılanmasında rol sahibi olduğu ifade edilmektedir. Hatta bu sentetik kannabinoidin indometazinle kıyaslandığında daha yüksek antiinflamatuvar yanıt oluşturduğu kaydedilmiştir [119]. Yine aynı sentetik kannabinoid analoğunun araştırıldığı bir diğer çalışmada Hepatit B virüsüne karşı antikor yanıtının oluşturulmasında ve bu yanıtın şiddetinin belirlenmesinde test edilen JWH-018 kannabinoidinin etkili olduğu belirlenmiştir [120].

\section{Kenevir ve Toksisite}

Kenevir preparatlarının, özellikle sentetik kannabinoidlerin kullanımından dolayı gelişen komplikasyonlar da mevcuttur. Kullanıma bağlı olarak anksiyete, uyku bozuklukları, hiperaktivite, ajitasyon, agresiflik gibi semptomlar bildirilmiştir. Akut intoksikasyon durumunda kısa süreli hafiza kaybı gibi bilişsel bozuklukların görüldüğü kaydedilmiştir. Manik durumlara rastlanabileceği gibi, paranoya, intihar eğilimleri gibi durumlara da sebebiyet verme ihtimallerinin mevcut olduğu ifade edilmektedir [121]. 
Içeriğinde CBD yer alan preparatların $\Delta 9$-THC'nin $\mathrm{CB} 1$ ve $\mathrm{CB} 2$ reseptörleri üzerinden gerçekleştirdiği fizyolojik ve toksikolojik etkilerin daha dengeli bir profil sergilediği görülmektedir. Sentetik kannabinoid preparatlarının CBD içerip içermemesi kadar, CB1 ve CB2 reseptörlerine yönelik daha yüksek afinite sergiliyor olmaları da farklı farmakolojik, fizyolojik ve toksikolojik etkinliklerini açıklar niteliktedir [121].

Kenevir praparatlarının intoksikasyonu durumunda hem çocuklar hem de yetişkinlerde tipik olarak hipertansiyon, taşikardi, nystagmus, solunuma dair sıkıntılar, uyku hali, ataksi, konuşma bozukluğu gibi anormalliklere rastlanmaktadır. Bebeklerde ise intoksikasyon durumunda ensefelopatiden açık komaya kadar değişen aralıkta semptomlar görülebilmektedir [122].

Son dönemlerde genellikle sentetik kannabinoid analoglarının kullanımı dolayısıyla intoksikasyon vaka sayılarının artışı dikkat çekmektedir. Intoksikasyon durumlarında genellikle vakaların hipertensiyon, taşikardi, halüsinasyon ve ajitasyon bulguları ortaya koyduğu görülmektedir [123].

\section{SONUÇ VE TARTIŞMA}

Elde edilen tüm bu bulguların ardından sonuç olarak; kenevir antik çağlardan bugüne tedavi maksatlı olarak pek çok kullanım imkanına sahip olmuştur. Kenevirin daha yaygın kullanıma sahip olmasının önüne psikoaktif özelliklere sahip olan $\triangle 9$-THC fitokannabinoidi geçmiştir. Bu sebeple çeşitli sınırlamalara maruz kalan kenevirin, günümüzde dikkat ve özenle hazırlanmış formülasyonlar ile psikoaktif özelliklerden ari bir şekilde terapötik etkinlik sergileyen preparatları da mevcuttur.

Nöropatik ağrıdan kansere, nörodejeneratif hastalıklardan bulantı/kusmaya kadar geniş bir hastalık skalasında araştırmalara konu olan kenevir, umut verici sonuçlar sergilemiştir. Gerçekleştirilen araştırmaların büyük çoğunluğu deneysel fazda yer alırken, daha kapsamlı araştırmalara ihtiyaç duyulan terapötik endikasyonlardan da söz etmek mümkündür. Kenevir içeriğindeki fitokannabinoid bileşenlerinden $\Delta$ 9-THC'nin MS hastalığında gözlenen kas spastisitesi ile kemoterapiye bağlı bulantı ve kusmada etkili olduğu, nöropatik ağrı tedavisinde de faydalı olabileceği belirlenmiştir. Aynı şekilde bir diğer fitokannabinoid olan CBD’nin ise epilepside faydalı veriler ortaya koyduğu görülmektedir. Bu bilgiler doğrultusunda ilgili endikasyonlar için kenevir temelli ilaçların onaylandığı bilinmektedir.

Sonuç olarak, kenevir ve içeriğindeki fitokannabinoidler terapötik etkinlik bakımından oldukça geniş yelpazede endikasyona hitap etmesi ile tıp dünyasının yoğun bir biçimde ilgisini çekmektedir. İçerdiği psikoaktif bileşenlere rağmen, uygun dozlarla doğru bir biçimde standardize edilmiş preparatların, kenevirin terapötik bir ajan olarak değerlendirilmesi yolculuğunda önemli bir mihenk taşı olacağı düşünülmektedir. Fitokannabinoidler ve kenevir ile ilişkili olarak; hem farklı endikasyonlar için hem de aynı endikasyonlarda daha kapsamlı, daha ayrıntılı veriler elde etmek için daha fazla çalışma ve araştırmaya ihtiyaç duyulmaktadır. 
İçerdiği fitokannabinoidlerle tıbbi yönden pek çok patolojik durumla ilişkilendirilebilen kenevir bitkisi, son dönemde tıp dünyasının literatür verilerinde kendisine sıklıkla yer bulmuştur. Bugüne kadar elde edilen verilere ek olarak, kenevir ve kannabinoidlere dair henüz gün yüzüne çıkarılmamış bilgiler göz önüne alındığında kenevirin terapötik potansiyelinin oldukça yüksek olduğu öngörülmektedir. Bu sebepledir ki; kenevirin gelecek y1llarda hem sahip olduğu potansiyel dolayısıyla artan bir ilgiyle karşılaşmaya devam edeceği hem de bilimsel araştırmalarda sıklıkla kendisine yer bulacağı düşünülmektedir.

\section{YAZAR KATKILARI}

Kavram: Ö.B., S.A.; Tasarım: Ö.B., S.A.; Denetim: S.A.; Kaynaklar: S.A.; Malzemeler: Ö.B.; Veri Toplama ve/veya işleme: Ö.B.; Analiz ve/veya yorumlama: S.A.; Literatür taraması: Ö.B.; Makalenin yazılması: Ö.B., S.A.; Kritik inceleme: Ö.B., S.A.; Diğer: -

\section{ÇIKAR ÇATIŞMASI BEYANI}

Yazarlar bu makale için gerçek, potansiyel veya algılanan çıkar çatışması olmadığını beyan ederler.

\section{KAYNAKLAR}

1. Maule, W. J. (2015). Medical uses of marijuana (Cannabis sativa): fact or fallacy? British Journal of Biomedical Science, 72(2), 85-91.[CrossRef]

2. Zuardi, A. W. (2006). History of cannabis as a medicine: a review. Brazilian Journal of Psychiatry, 28, 153-157. [CrossRef]

3. Kalant, H. (2001). Medicinal use of cannabis: history and current status. Pain Res Manag, 6(2), 80-91. [CrossRef]

4. Touw, M. (1981). The Religious and Medicinal Uses of Cannabis in China, India and Tibet. Journal of Psychoactive Drugs, 13(1), 23-34. [CrossRef]

5. Pisanti, S., Bifulco, M. (2017). Modern History of Medical Cannabis: From Widespread Use to Prohibitionism and Back. Trends in Pharmacological Sciences, 38(3), 195-198. [CrossRef]

6. Amin, M. R., Ali, D. W. (2019). Pharmacology of Medical Cannabis. Adv Exp Med Biol, 1162, 151-165. [CrossRef]

7. Turan, M., (2000). Lif Bitkileri. Bursa: Uludağ Üniversitesi Ziraat Fakültesi Tarla Bitkilleri Bölümü,. 
8. Aydoğan, M., Terzi, Y. E., Gizlenci, Ş., Acar, M., Esen, A., Meral, H. (2020). Türkiye'de kenevir yetiştiriciliğinin ekonomik olarak yapılabilirliği: Samsun ili Vezirköprü ilçesi örneği. ANADOLU JOURNAL OF AGRICULTURAL SCIENCES, 35, 35-50. [CrossRef]

9. $\quad$ Ağar, Osman T. (2019). "Cannabis’e Tarihsel Bir Bakış." Estüdam Halk Sağliği Dergisi , pp.711 .

10. Koca Çalışkan, U, Yıldırım, S . (2020) "Kenevir Ve Sağlık Alanında Kullanımı" . Journal of Faculty of Pharmacy of Ankara University, 44: 112-136. [CrossRef]

11. Onay, A., Yıldırım, H., Ekinci, R. (2020). Kenevir, Cannabis sativa L. Ankara: Palme Yayınevi.

12. ElSohly, M. A., Radwan, M. M., Gul, W., Chandra, S., Galal, A. (2017). Phytochemistry of Cannabis sativa L. Prog Chem Org Nat Prod, 103, 1-36. [CrossRef]

13. Pertwee, R. G. (2008). The diverse CB1 and CB2 receptor pharmacology of three plant cannabinoids: delta9-tetrahydrocannabinol, cannabidiol and delta9-tetrahydrocannabivarin. British journal of pharmacology, 153(2), 199-215. [CrossRef]

14. Crippa, J. A., Zuardi, A. W., Martín-Santos, R., Bhattacharyya, S., Atakan, Z., McGuire, P., Fusar-Poli, P. (2009). Cannabis and anxiety: a critical review of the evidence. Hum Psychopharmacol, 24(7), 515-523. [CrossRef]

15. Zuardi, A. W., Morais, S. L., Guimarães, F. S., Mechoulam, R. (1995). Antipsychotic effect of cannabidiol. J Clin Psychiatry, 56(10), 485-486. [CrossRef]

16. Mechoulam, R., Peters, M., Murillo-Rodriguez, E., Hanus, L. O. (2007). Cannabidiol--recent advances. Chem Biodivers, 4(8), 1678-1692. [CrossRef]

17. Console-Bram, L., Marcu, J., Abood, M. E. (2012). Cannabinoid receptors: nomenclature and pharmacological principles. Progress in Neuro-Psychopharmacology and Biological Psychiatry, 38(1), 4-15. [CrossRef]

18. Svíženská, I., Dubový, P., Šulcová, A. (2008). Cannabinoid receptors 1 and 2 (CB1 and CB2), their distribution, ligands and functional involvement in nervous system structures - A short review. Pharmacology Biochemistry and Behavior, 90(4), 501-511. [CrossRef]

19. Kendall, D. A., Yudowski, G. A. (2017). Cannabinoid Receptors in the Central Nervous System: Their Signaling and Roles in Disease. Frontiers in Cellular Neuroscience, 10(294). [CrossRef]

20. Szulakowska, A., Milnerowicz, H. (2007). Cannabis sativa in the Light of Scientific Research. Advances in Clinical and Experimental Medicine, 16, 807-815.

21. Onaivi, E. S., Ishiguro, H., Gong, J.-P., Patel, S., Perchuk, A., Meozzi, P. A., Uhl, G. R. (2006). Discovery of the Presence and Functional Expression of Cannabinoid CB2 Receptors in Brain. Annals of the New York Academy of Sciences, 1074(1), 514-536. [CrossRef]

22. Van Sickle, M. D., Duncan, M., Kingsley, P. J., Mouihate, A., Urbani, P., Mackie, K., Sharkey, K. A. (2005). Identification and Functional Characterization of Brainstem Cannabinoid $\mathrm{CB}<\mathrm{sub}>2</$ sub $>$ Receptors. Science, 310(5746), 329-332. [CrossRef]

23. Henstridge, C. M. (2012). Off-Target Cannabinoid Effects Mediated by GPR55. Pharmacology, 89(3-4), 179-187. [CrossRef] 
24. Katchan, V., David, P.,Shoenfeld, Y. (2016). Cannabinoids and autoimmune diseases: A systematic review. Autoimmunity Reviews, 15(6), 513-528. [CrossRef]

25. Laprairie, R. B., Bagher, A. M., Denovan-Wright, E. M. (2017). Cannabinoid receptor ligand bias: implications in the central nervous system. Current Opinion in Pharmacology, 32, 32-43. [CrossRef]

26. Cunha, P., Romão, A., Mascarenhas-Melo, F., Teixeira, H., Reis, F. (2011). Endocannabinoid system in cardiovascular disorders - new pharmacotherapeutic opportunities. Journal of Pharmacy And Bioallied Sciences, 3(3), 350-360. [CrossRef]

27. Pagotto, U., Marsicano, G., Cota, D., Lutz, B., Pasquali, R. (2006). The Emerging Role of the Endocannabinoid System in Endocrine Regulation and Energy Balance. Endocrine Reviews, 27(1), 73-100. doi:10.1210/er.2005-0009

28. Bridgeman, M. B., Abazia, D. T. (2017). Medicinal Cannabis: History, Pharmacology, And Implications for the Acute Care Setting. $P \& T:$ a peer-reviewed journal for formulary management, 42(3), 180-188. [CrossRef]

29. Di Marzo, V. (2008). Targeting the endocannabinoid system: to enhance or reduce? Nat Rev Drug Discov, 7(5), 438-455. [CrossRef]

30. Pacher, P., Mechoulam, R. (2011). Is lipid signaling through cannabinoid 2 receptors part of a protective system? Progress in Lipid Research, 50(2), 193-211. [CrossRef]

31. Hasenoehrl, C., Taschler, U., Storr, M., Schicho, R. (2016). The gastrointestinal tract - a central organ of cannabinoid signaling in health and disease. Neurogastroenterology \& Motility, 28(12), 1765-1780. [CrossRef]

32. Ligresti, A., Petrocellis, L. D., Marzo, V. D. (2016). From Phytocannabinoids to Cannabinoid Receptors and Endocannabinoids: Pleiotropic Physiological and Pathological Roles Through Complex Pharmacology. Physiological Reviews, 96(4), 1593-1659. [CrossRef]

33. Benito, C., Romero, J. P., Tolón, R. M., Clemente, D., Docagne, F., Hillard, C. J., Romero, J. (2007). Cannabinoid CB\&lt;sub\&gt;1\&lt;/sub\&gt; and CB\&lt;sub\&gt;2\&lt;/sub\&gt; Receptors and Fatty Acid Amide Hydrolase Are Specific Markers of Plaque Cell Subtypes in Human Multiple Sclerosis. The Journal of Neuroscience, 27(9), 2396. [CrossRef]

34. Jean-Gilles, L., Feng, S., Tench, C. R., Chapman, V., Kendall, D. A., Barrett, D. A., Constantinescu, C. S. (2009). Plasma endocannabinoid levels in multiple sclerosis. Journal of the Neurological Sciences, 287(1), 212-215. [CrossRef]

35. Killestein, J., Hoogervorst, E. L., Reif, M., Kalkers, N. F., Van Loenen, A. C., Staats, P. G., Polman, C. H. (2002). Safety, tolerability, and efficacy of orally administered cannabinoids in MS. Neurology, 58(9), 1404-1407. [CrossRef]

36. Ungerleider, J. T., Andyrsiak, T., Fairbanks, L., Ellison, G. W., Myers, L. W. (1987). Delta-9THC in the treatment of spasticity associated with multiple sclerosis. Adv Alcohol Subst Abuse, 7(1), 39-50. [CrossRef] 
37. Zajicek, J. P., Hobart, J. C., Slade, A., Barnes, D., Mattison, P. G. (2012). MUltiple Sclerosis and Extract of Cannabis: results of the MUSEC trial. Journal of Neurology, Neurosurgery \&amp;amp; Psychiatry, 83(11), 1125. [CrossRef]

38. Collin, C., Ehler, E., Waberzinek, G., Alsindi, Z., Davies, P., Powell, K., Ambler, Z. (2010). A double-blind, randomized, placebo-controlled, parallel-group study of Sativex, in subjects with symptoms of spasticity due to multiple sclerosis. Neurological Research, 32(5), 451-459. [CrossRef]

39. Wade, D. T., Makela, P., Robson, P., House, H.,Bateman, C. (2004). Do cannabis-based medicinal extracts have general or specific effects on symptoms in multiple sclerosis? A doubleblind, randomized, placebo-controlled study on 160 patients. Multiple Sclerosis Journal, 10(4), 434-441. [CrossRef]

40. Rog, D. J., Nurmikko, T. J., Young, C. A. (2007). Oromucosal $\Delta 9-$ tetrahydrocannabinol/cannabidiol for neuropathic pain associated with multiple sclerosis: An uncontrolled, open-label, 2-year extension trial. Clinical Therapeutics, 29(9), 2068-2079. [CrossRef]

41. Wallace, M. J., Blair, R. E., Falenski, K. W., Martin, B. R., DeLorenzo, R. J. (2003). The Endogenous Cannabinoid System Regulates Seizure Frequency and Duration in a Model of Temporal Lobe Epilepsy. Journal of Pharmacology and Experimental Therapeutics, 307(1), 129. [CrossRef]

42. Ellison, J. M., Gelwan, E., Ogletree, J. (1990). Complex partial seizure symptoms affected by marijuana abuse. J Clin Psychiatry, 51(10), 439-440. [CrossRef]

43. Gross, D. W., Hamm, J., Ashworth, N. L., Quigley, D. (2004). Marijuana use and epilepsy: prevalence in patients of a tertiary care epilepsy center. Neurology, 62(11), 2095-2097. [CrossRef]

44. Mortati, K., Dworetzky, B., Devinsky, O. (2007). Marijuana: an effective antiepileptic treatment in partial epilepsy? A case report and review of the literature. Rev Neurol Dis, 4(2), 103-106.

45. Hamerle, M., Ghaeni, L., Kowski, A., Weissinger, F., Holtkamp, M. (2014). Cannabis and other illicit drug use in epilepsy patients. European Journal of Neurology, 21(1), 167-170. [CrossRef]

46. Hussain, S. A., Zhou, R., Jacobson, C., Weng, J., Cheng, E., Lay, J., Sankar, R. (2015). Perceived efficacy of cannabidiol-enriched cannabis extracts for treatment of pediatric epilepsy: A potential role for infantile spasms and Lennox-Gastaut syndrome. Epilepsy \& Behavior, 47, 138-141. [CrossRef]

47. Porter, B. E., Jacobson, C. (2013). Report of a parent survey of cannabidiol-enriched cannabis use in pediatric treatment-resistant epilepsy. Epilepsy \& Behavior, 29(3), 574-577. [CrossRef]

48. Gofshteyn, J. S., Wilfong, A., Devinsky, O., Bluvstein, J., Charuta, J., Ciliberto, M. A., Marsh, E. D. (2017). Cannabidiol as a Potential Treatment for Febrile Infection-Related Epilepsy Syndrome (FIRES) in the Acute and Chronic Phases. Journal of Child Neurology, 32(1), 35-40. [CrossRef]

49. Suraev, A., Lintzeris, N., Stuart, J., Kevin, R. C., Blackburn, R., Richards, E., McGregor, I. S. (2018). Composition and Use of Cannabis Extracts for Childhood Epilepsy in the Australian Community. Scientific Reports, 8(1), 10154. [CrossRef] 
50. Stampanoni Bassi M., (2017). Cannabinoids in Parkinson's Disease.. Cannabis and Cannabinoid Research, 2(1), 21-29. [CrossRef]

51. Basavarajappa, B. S., Shivakumar, M., Joshi, V., Subbanna, S. (2017). Endocannabinoid system in neurodegenerative disorders. J Neurochem, 142(5), 624-648. [CrossRef]

52. Hurley, M. J., Mash, D. C., Jenner, P. (2003b). Expression of cannabinoid CB1 receptor mRNA in basal ganglia of normal and parkinsonian human brain. J Neural Transm (Vienna), 110(11), 1279-1288. [CrossRef]

53. Hurley, M. J., Mash, D. C., Jenner, P. (2003a). Expression of cannabinoid CB1 receptor mRNA in basal ganglia of normal and parkinsonian human brain. Journal of Neural Transmission, 110(11), 1279-1288. [CrossRef]

54. El Banoua, F., Caraballo, I., Flores, J. A., Galan-Rodriguez, B., Fernandez-Espejo, E. (2004). Effects on turning of microinjections into basal ganglia of D1 and D2 dopamine receptors agonists and the cannabinoid CB1 antagonist SR141716A in a rat Parkinson's model. Neurobiology of Disease, 16(2), 377-385. [CrossRef]

55. Kelsey, J. E., Harris, O., Cassin, J. (2009). The CB1 antagonist rimonabant is adjunctively therapeutic as well as monotherapeutic in an animal model of Parkinson's disease. Behavioural Brain Research, 203(2), 304-307. [CrossRef]

56. Meschler, J. P., Howlett, A. C., Madras, B. K. (2001). Cannabinoid receptor agonist and antagonist effects on motor function in normal and 1-methyl-4-phenyl-1,2,5,6tetrahydropyridine (MPTP)-treated non-human primates. Psychopharmacology (Berl), 156(1), 79-85. [CrossRef]

57. Benito, C., Núñez, E., Tolón, R. M., Carrier, E. J., Rábano, A., Hillard, C. J., Romero, J. (2003). Cannabinoid CB2 receptors and fatty acid amide hydrolase are selectively overexpressed in neuritic plaque-associated glia in Alzheimer's disease brains. J Neurosci, 23(35), 11136-11141. [CrossRef]

58. Ramírez, B. G., Blázquez, C., del Pulgar, T. G., Guzmán, M., de Ceballos, M. L. (2005). Prevention of Alzheimer\&\#039;s Disease Pathology by Cannabinoids: Neuroprotection Mediated by Blockade of Microglial Activation. The Journal of Neuroscience, 25(8), 1904. [CrossRef]

59. Koppel, J., Vingtdeux, V., Marambaud, P., d'Abramo, C., Jimenez, H., Stauber, M., Davies, P. (2014). CB2 Receptor Deficiency Increases Amyloid Pathology and Alters Tau Processing in a Transgenic Mouse Model of Alzheimer's Disease. Molecular Medicine, 20(1), 29-36. [CrossRef]

60. Solas, M., Francis, P. T., Franco, R., Ramirez, M. J. (2013). CB2 receptor and amyloid pathology in frontal cortex of Alzheimer's disease patients. Neurobiology of Aging, 34(3), 805808. [CrossRef]

61. Tolón, R. M., Núñez, E., Pazos, M. R., Benito, C., Castillo, A. I., Martínez-Orgado, J. A., Romero, J. (2009). The activation of cannabinoid CB2 receptors stimulates in situ and in vitro beta-amyloid removal by human macrophages. Brain Research, 1283, 148-154. [CrossRef] 
62. Wu, J., Bie, B., Yang, H., Xu, J. J., Brown, D. L., Naguib, M. (2013). Activation of the CB2 receptor system reverses amyloid-induced memory deficiency. Neurobiology of Aging, 34(3), 791-804. [CrossRef]

63. Esposito, G., Scuderi, C., Savani, C., Steardo Jr, L., De Filippis, D., Cottone, P.,Steardo, L. (2007). Cannabidiol in vivo blunts $\beta$-amyloid induced neuroinflammation by suppressing IL- $1 \beta$ and iNOS expression. British journal of pharmacology, 151(8), 1272-1279. [CrossRef]

64. Glass, M., Faull, R. L., Dragunow, M. (1993). Loss of cannabinoid receptors in the substantia nigra in Huntington's disease. Neuroscience, 56(3), 523-527. [CrossRef]

65. Richfield, E. K., Herkenham, M. (1994). Selective vulnerability in Huntington's disease: Preferential loss of cannabinoid receptors in lateral globus pallidus. Annals of Neurology, 36(4), 577-584. [CrossRef]

66. Denovan-Wright, E. M., Robertson, H. A. (2000). Cannabinoid receptor messenger RNA levels decrease in a subset of neurons of the lateral striatum, cortex and hippocampus of transgenic Huntington's disease mice. Neuroscience, 98(4), 705-713. [CrossRef]

67. Dowie, M. J., Bradshaw, H. B., Howard, M. L., Nicholson, L. F., Faull, R. L., Hannan, A. J., Glass, M. (2009). Altered CB1 receptor and endocannabinoid levels precede motor symptom onset in a transgenic mouse model of Huntington's disease. Neuroscience, 163(1), 456-465. [CrossRef]

68. McCaw, E. A., Hu, H., Gomez, G. T., Hebb, A. L., Kelly, M. E., Denovan-Wright, E. M. (2004). Structure, expression and regulation of the cannabinoid receptor gene (CB1) in Huntington's disease transgenic mice. Eur J Biochem, 271(23-24), 4909-4920. [CrossRef]

69. Consroe, P., Laguna, J., Allender, J., Snider, S., Stern, L., Sandyk, R., Schram, K. (1991). Controlled clinical trial of cannabidiol in Huntington's disease. Pharmacol Biochem Behav, 40(3), 701-708. [CrossRef]

70. López-Sendón Moreno, J. L., García Caldentey, J., Trigo Cubillo, P., Ruiz Romero, C., García Ribas, G., Alonso Arias, M. A. A., García de Yébenes Prous, J. (2016). A double-blind, randomized, cross-over, placebo-controlled, pilot trial with Sativex in Huntington's disease. Journal of Neurology, 263(7), 1390-1400. [CrossRef]

71. Curtis, A., Mitchell, I., Patel, S., Ives, N., Rickards, H. (2009). A pilot study using nabilone for symptomatic treatment in Huntington's disease. Movement Disorders, 24(15), 2254-2259. [CrossRef]

72. Alles, S. R. A., Smith, P. A. (2018). Etiology and Pharmacology of Neuropathic Pain. Pharmacol Rev, 70(2), 315-347. [CrossRef]

73. Abrams, D. I., Jay, C. A., Shade, S. B., Vizoso, H., Reda, H., Press, S., . Petersen, K. L. (2007). Cannabis in painful HIV-associated sensory neuropathy: a randomized placebo-controlled trial. Neurology, 68(7), 515-521. [CrossRef]

74. Ellis, R. J., Toperoff, W., Vaida, F., van den Brande, G., Gonzales, J., Gouaux, B., Atkinson, J. H. (2009). Smoked medicinal cannabis for neuropathic pain in HIV: a randomized, crossover clinical trial. Neuropsychopharmacology, 34(3), 672-680. [CrossRef] 
75. Wilsey, B., Marcotte, T., Tsodikov, A., Millman, J., Bentley, H., Gouaux, B.,Fishman, S. (2008). A randomized, placebo-controlled, crossover trial of cannabis cigarettes in neuropathic pain. The journal of pain : official journal of the American Pain Society, 9(6), 506-521. [CrossRef]

76. Borgelt, L. M., Franson, K. L., Nussbaum, A. M., Wang, G. S. (2013). The pharmacologic and clinical effects of medical cannabis. Pharmacotherapy, 33(2), 195-209. [CrossRef]

77. Nurmikko, T. J., Serpell, M. G., Hoggart, B., Toomey, P. J., Morlion, B. J., Haines, D. (2007). Sativex successfully treats neuropathic pain characterised by allodynia: a randomised, doubleblind, placebo-controlled clinical trial. Pain, 133(1-3), 210-220. [CrossRef]

78. Rog, D. J., Nurmikko, T. J.,Young, C. A. (2007). Oromucosal delta9tetrahydrocannabinol/cannabidiol for neuropathic pain associated with multiple sclerosis: an uncontrolled, open-label, 2-year extension trial. Clin Ther, 29(9), 2068-2079. [CrossRef]

79. Häuser, W., Fitzcharles, M. A., Radbruch, L., Petzke, F. (2017). Cannabinoids in Pain Management and Palliative Medicine. Dtsch Arztebl Int, 114(38), 627-634. [CrossRef]

80. Fitzcharles, M. A., Baerwald, C., Ablin, J., Häuser, W. (2016). Efficacy, tolerability and safety of cannabinoids in chronic pain associated with rheumatic diseases (fibromyalgia syndrome, back pain, osteoarthritis, rheumatoid arthritis): A systematic review of randomized controlled trials. Schmerz, 30(1), 47-61. [CrossRef]

81. Fitzcharles, M. A., Ste-Marie, P. A., Häuser, W., Clauw, D. J., Jamal, S., Karsh, J.,Walsh, Z. (2016). Efficacy, Tolerability, and Safety of Cannabinoid Treatments in the Rheumatic Diseases: A Systematic Review of Randomized Controlled Trials. Arthritis Care Res (Hoboken), 68(5), 681-688. [CrossRef]

82. Fraguas-Sánchez, A. I., Martín-Sabroso, C., Torres-Suárez, A. I. (2018). Insights into the effects of the endocannabinoid system in cancer: a review. British journal of pharmacology, 175(13), 2566-2580. [CrossRef]

83. Sredni, S. T., Huang, C.-C., Suzuki, M., Pundy, T., Chou, P., Tomita, T. (2016). Spontaneous involution of pediatric low-grade gliomas: high expression of cannabinoid receptor 1 (CNR1) at the time of diagnosis may indicate involvement of the endocannabinoid system. Child's Nervous System, 32(11), 2061-2067. [CrossRef]

84. Wu, X., Han, L., Zhang, X., Li, L., Jiang, C., Qiu, Y., Fu, J. (2012). Alteration of endocannabinoid system in human gliomas. Journal of Neurochemistry, 120(5), 842-849. [CrossRef]

85. Ellert-Miklaszewska, A., Grajkowska, W., Gabrusiewicz, K., Kaminska, B., Konarska, L. (2007). Distinctive pattern of cannabinoid receptor type II (CB2) expression in adult and pediatric brain tumors. Brain Res, 1137(1), 161-169. [CrossRef]

86. Sánchez, C., de Ceballos, M. L., Gomez del Pulgar, T., Rueda, D., Corbacho, C., Velasco, G.,Guzmán, M. (2001). Inhibition of glioma growth in vivo by selective activation of the $\mathrm{CB}(2)$ cannabinoid receptor. Cancer Res, 61(15), 5784-5789.

87. Schley, M., Ständer, S., Kerner, J., Vajkoczy, P., Schüpfer, G., Dusch, M., Konrad, C. (2009). Predominant CB2 receptor expression in endothelial cells of glioblastoma in humans. Brain Res Bull, 79(5), 333-337. [CrossRef] 
88. Hohmann, T., Grabiec, U., Ghadban, C., Feese, K., Dehghani, F. (2017). The influence of biomechanical properties and cannabinoids on tumor invasion. Cell adhesion \& migration, 11(1), 54-67. [CrossRef]

89. Ma, C., Wu, T.-T., Jiang, P.-C., Li, Z.-Q., Chen, X.-J., Fu, K., Gong, R. (2016). Anticarcinogenic activity of anandamide on human glioma in vitro and in vivo. Molecular medicine reports, 13(2), 1558-1562. [CrossRef]

90. Fowler, C. J., Jonsson, K. O., Andersson, A., Juntunen, J., Järvinen, T., Vandevoorde, S., .Smart, D. (2003). Inhibition of C6 glioma cell proliferation by anandamide, 1-arachidonoylglycerol, and by a water soluble phosphate ester of anandamide: variability in response and involvement of arachidonic acid. Biochem Pharmacol, 66(5), 757-767. [CrossRef]

91. Jacobsson, S. O., Wallin, T., Fowler, C. J. (2001). Inhibition of rat C6 glioma cell proliferation by endogenous and synthetic cannabinoids. Relative involvement of cannabinoid and vanilloid receptors. J Pharmacol Exp Ther, 299(3), 951-959. [CrossRef]

92. Caffarel, M. M., Andradas, C., Mira, E., Pérez-Gómez, E., Cerutti, C., Moreno-Bueno, G., Sánchez, C. (2010). Cannabinoids reduce ErbB2-driven breast cancer progression through Akt inhibition. Mol Cancer, 9, 196. [CrossRef]

93. Bisogno, T., Katayama, K., Melck, D., Ueda, N., De Petrocellis, L., Yamamoto, S., Di Marzo, V. (1998). Biosynthesis and degradation of bioactive fatty acid amides in human breast cancer and rat pheochromocytoma cells--implications for cell proliferation and differentiation. Eur $J$ Biochem, 254(3), 634-642. [CrossRef]

94. Melck, D., De Petrocellis, L., Orlando, P., Bisogno, T., Laezza, C., Bifulco, M., Di Marzo, V. (2000). Suppression of nerve growth factor Trk receptors and prolactin receptors by endocannabinoids leads to inhibition of human breast and prostate cancer cell proliferation. Endocrinology, 141(1), 118-126. [CrossRef]

95. Ligresti, A., Moriello, A. S., Starowicz, K., Matias, I., Pisanti, S., De Petrocellis, L., Di Marzo, V. (2006). Antitumor activity of plant cannabinoids with emphasis on the effect of cannabidiol on human breast carcinoma. J Pharmacol Exp Ther, 318(3), 1375-1387. [CrossRef]

96. Qamri, Z., Preet, A., Nasser, M. W., Bass, C. E., Leone, G., Barsky, S. H., Ganju, R. K. (2009). Synthetic cannabinoid receptor agonists inhibit tumor growth and metastasis of breast cancer. Mol Cancer Ther, 8(11), 3117-3129. [CrossRef]

97. Chung, S. C., Hammarsten, P., Josefsson, A., Stattin, P., Granfors, T., Egevad, L., Fowler, C. J. (2009). A high cannabinoid CB(1) receptor immunoreactivity is associated with disease severity and outcome in prostate cancer. Eur J Cancer, 45(1), 174-182. [CrossRef]

98. Cipriano, M., Häggström, J., Hammarsten, P., Fowler, C. J. (2013). Association between Cannabinoid CB1 Receptor Expression and Akt Signalling in Prostate Cancer. PLoS One, 8(6), e65798. [CrossRef]

99. Orellana-Serradell, O., Poblete, C. E., Sanchez, C., Castellón, E. A., Gallegos, I., Huidobro, C., Contreras, H. R. (2015). Proapoptotic effect of endocannabinoids in prostate cancer cells. Oncol Rep, 33(4), 1599-1608. [CrossRef] 
100. Sarfaraz, S., Afaq, F., Adhami, V. M., Mukhtar, H. (2005). Cannabinoid receptor as a novel target for the treatment of prostate cancer. Cancer Res, 65(5), 1635-1641. [CrossRef]

101. Mimeault, M., Pommery, N., Wattez, N., Bailly, C., Hénichart, J. P. (2003). Anti-proliferative and apoptotic effects of anandamide in human prostatic cancer cell lines: implication of epidermal growth factor receptor down-regulation and ceramide production. Prostate, 56(1), 112. [CrossRef]

102. Nithipatikom, K., Isbell, M. A., Endsley, M. P., Woodliff, J. E., Campbell, W. B. (2011). Antiproliferative effect of a putative endocannabinoid, 2-arachidonylglyceryl ether in prostate carcinoma cells. Prostaglandins \& other lipid mediators, 94(1-2), 34-43. [CrossRef]

103. DeMorrow, S., Francis, H., Gaudio, E., Venter, J., Franchitto, A., Kopriva, S., Alpini, G. (2008). The endocannabinoid anandamide inhibits cholangiocarcinoma growth via activation of the noncanonical Wnt signaling pathway. American journal of physiology. Gastrointestinal and liver physiology, 295(6), G1150-G1158. [CrossRef]

104. Frampton, G., Coufal, M., Li, H., Ramirez, J., DeMorrow, S. (2010). Opposing actions of endocannabinoids on cholangiocarcinoma growth is via the differential activation of Notch signaling. Experimental cell research, 316(9), 1465-1478. [CrossRef]

105. Ramer, R., Schwarz, R., Hinz, B. (2019). Modulation of the Endocannabinoid System as a Potential Anticancer Strategy. Frontiers in pharmacology, 10, 430-430. [CrossRef]

106. Vara, D., Salazar, M., Olea-Herrero, N., Guzmán, M., Velasco, G., Díaz-Laviada, I. (2011). Anti-tumoral action of cannabinoids on hepatocellular carcinoma: role of AMPK-dependent activation of autophagy. Cell Death Differ, 18(7), 1099-1111. [CrossRef]

107. Xu, D., Wang, J., Zhou, Z., He, Z., Zhao, Q. (2015). Cannabinoid WIN55, 212-2 induces cell cycle arrest and inhibits the proliferation and migration of human BEL7402 hepatocellular carcinoma cells Corrigendum in /mmr/13/1/1054. Mol Med Rep, 12(6), 7963-7970. [CrossRef]

108. Sallan, S. E., Zinberg, N. E., Frei, E., 3rd. (1975). Antiemetic effect of delta-9tetrahydrocannabinol in patients receiving cancer chemotherapy. N Engl J Med, 293(16), 795797. [CrossRef]

109. Darmani, N. A. (2001b). Delta(9)-tetrahydrocannabinol and synthetic cannabinoids prevent emesis produced by the cannabinoid $\mathrm{CB}(1)$ receptor antagonist/inverse agonist SR 141716A. Neuropsychopharmacology, 24(2), 198-203. [CrossRef]

110. Darmani, N. A. (2001a). Delta-9-tetrahydrocannabinol differentially suppresses cisplatininduced emesis and indices of motor function via cannabinoid $\mathrm{CB}(1)$ receptors in the least shrew. Pharmacol Biochem Behav, 69(1-2), 239-249. [CrossRef]

111. Pomeroy, M., Fennelly, J. J., Towers, M. (1986). Prospective randomized double-blind trial of nabilone versus domperidone in the treatment of cytotoxic-induced emesis. Cancer Chemother Pharmacol, 17(3), 285-288. [CrossRef]

112. Meiri, E., Jhangiani, H., Vredenburgh, J. J., Barbato, L. M., Carter, F. J., Yang, H. M., Baranowski, V. (2007). Efficacy of dronabinol alone and in combination with ondansetron versus ondansetron alone for delayed chemotherapy-induced nausea and vomiting. Curr Med Res Opin, 23(3), 533-543. [CrossRef] 
113. Polito, S., MacDonald, T., Romanick, M., Jupp, J., Wiernikowski, J., Vennettilli, A., Dupuis, L. L. (2018). Safety and efficacy of nabilone for acute chemotherapy-induced vomiting prophylaxis in pediatric patients: A multicenter, retrospective review. Pediatr Blood Cancer, 65(12), e27374. [CrossRef]

114. Kleine-Brueggeney, M., Greif, R., Brenneisen, R., Urwyler, N., Stueber, F., Theiler, L. G. (2015). Intravenous Delta-9-Tetrahydrocannabinol to Prevent Postoperative Nausea and Vomiting: A Randomized Controlled Trial. Anesth Analg, 121(5), 1157-1164. [CrossRef]

115. Pellati, F., Borgonetti, V., Brighenti, V., Biagi, M., Benvenuti, S., Corsi, L. (2018). Cannabis sativa L. and Nonpsychoactive Cannabinoids: Their Chemistry and Role against Oxidative Stress, Inflammation, and Cancer. BioMed research international, 2018, 1691428. [CrossRef]

116. Costa, B., Colleoni, M., Conti, S., Parolaro, D., Franke, C., Trovato, A. E., Giagnoni, G. (2004). Oral anti-inflammatory activity of cannabidiol, a non-psychoactive constituent of cannabis, in acute carrageenan-induced inflammation in the rat paw. Naunyn-Schmiedeberg's archives of pharmacology, 369(3), 294-299. [CrossRef]

117. Petrosino, S., Verde, R., Vaia, M., Allarà, M., Iuvone, T., Di Marzo, V. (2018). Antiinflammatory Properties of Cannabidiol, a Nonpsychotropic Cannabinoid, in Experimental Allergic Contact Dermatitis. The Journal of pharmacology and experimental therapeutics, 365(3), 652-663. [CrossRef]

118. Mackie, K., Stella, N. (2006). Cannabinoid receptors and endocannabinoids: evidence for new players. The AAPS journal, 8(2), E298-E306. [CrossRef]

119. Parlakpınar, Hakan Celbis, Osman Ozhan, Onural Petekkaya, Semih Samdanci, Emine Ermis, Necip Koparir, Pelin Soylu, Ozcan Acet, Ahmet. (2016). Cardiovascular effects of JWH-018 from synthetic cannabinoids [Sentetik kannabinoidlerden JWH-018'in kardiyovaskuler etkileri], Medicine Science., 5. 1. [CrossRef]

120. Köksoy S , Başalp A . (2021). Effect of synthetic cannabinoids (JWH-018) on antibody response to HBV vaccination, Mehmet Akif Ersoy Üniversitesi Sağllk Bilimleri Enstitüsü Dergisi, 2021; 9(1): 21-26. [CrossRef]

121. Kogan, N. M., Mechoulam, R. (2007). Cannabinoids in health and disease. Dialogues in clinical neuroscience, 9(4), 413-430. [CrossRef]

122. Wong, K. U., Baum, C. R. (2019). Acute Cannabis Toxicity. Pediatric emergency care, 35(11), 799-804. [CrossRef]

123. Kuzucuoğlu, T., Uçkun, S., Temizel, F., Arslan, G., Çevik, B. (2018). Kannabinoid İntoksikasyonlarının Yoğun Bakım Sonuçları: Olgu Serisi. Dahili ve Cerrahi Bilimler Yoğun Bakım Dergisi.; 9(3): 84 - 87. [CrossRef] 